\title{
The Peculiarities of Contact Potential Difference and Energy
} Characteristics of Metal Boundaries

\author{
V. M. Yuzevich ${ }^{1}$, B. P. Koman ${ }^{2}$, and R. Dzhala ${ }^{1}$ \\ ${ }^{1}$ H. V. Karpenko Physicomechanical Institute, N.A.S. of Ukraine, \\ 5, Naukova Str., \\ 79601 Lviv, Ukraine \\ ${ }^{2}$ Ivan Franko National University of Lviv, \\ 50 Drahomanov Str., \\ 79005 Lviv, Ukraine
}

Based on the relations of nonequilibrium thermodynamics and mechanics of a deformed solid, physical-mathematical model of interface boundary of contacting metals is proposed for determining the energy characteristics of near-surface layers and contact potential difference. The interfaciallayers' energy parameters (interfacial energy $W_{m}$, interfacial tension $\sigma_{m}$, and energy of adhesive bonds $W_{a d}$ for contacting metals $\mathrm{Cr}, \mathrm{Fe}, \mathrm{Al}, \mathrm{Ni}$, $\mathrm{Cu}, \mathrm{Zn}, \mathrm{Ti}, \mathrm{Sn}, \mathrm{Pb}$ ) are calculated. The internal contact potential difference $\Delta \phi_{Y}$ (CPD) between metals under taking into account the energy parameters of interphase layer is evaluated. The comparison of the CPD calculation with similar known methods is carried out.

Запропоновано фізико-математичний модель межі поділу контактувальних металів на основі співвідношень нерівноважної термодинаміки та механіки деформовного твердого тіла для визначення енергетичних характеристик приповерхневих шарів і контактної ріжниці потенціялів. Проведено розрахунок енергетичних характеристик міжфазових шарів: міжфазної енергії $W_{m}$, міжфазного натягу $\sigma_{m}$ та енергії адгезійних зв'язків $W_{a d}$ для контактувальних металів $\mathrm{Cr}, \mathrm{Fe}, \mathrm{Al}, \mathrm{Ni}, \mathrm{Cu}, \mathrm{Zn}$, $\mathrm{Ti}, \mathrm{Sn}, \mathrm{Pb}$. Оцінено внутрішню контактну ріжницю потенціялів $\Delta \phi_{Y}$ (КРП) між металами з урахуванням енергетичних параметрів міжфазового шару. Виконано порівняння одержаних оцінок КРП з аналогічними, одержаними за відомими методиками.

Предложена физико-математическая модель границы раздела контактирующих металлов на основании соотношений неравновесной термодинамики и механики деформируемого твёрдого тела для определения энергетических характеристик приповерхностных слоёв и контактной разности потенциалов. Рассчитаны энергетические характеристики 
межфазных слоёв: межфазной энергии $W_{m}$, межфазного натяжения $\sigma_{m}$ и энергии адгезионных связей $W_{a d}$ для контактирующих металлов $\mathrm{Cr}$, $\mathrm{Fe}, \mathrm{Al}, \mathrm{Ni}, \mathrm{Cu}, \mathrm{Zn}, \mathrm{Ti}, \mathrm{Sn}, \mathrm{Pb}$. Проведена оценка внутренней контактной разности потенциалов $\Delta \phi_{Y}(\kappa Р \Pi)$ между металлами с учётом энергетических параметров межфазного слоя. Проведено сравнение полученных оценок КРП с аналогичными, полученными с помощью известных методик.

Key words: metals, interphase interaction, contact potential difference (CPD), energy parameters.

Ключові слова: метали, міжфазова взаємодія, контактна ріжниця потенціялів, енергетичні характеристики.

Ключевые слова: металлы, межфазное взаимодействие, контактная разность потенциалов, энергетические характеристики.

(Received 22 November, 2017)

\section{INTRODUCTION}

It is believed that, at the contact of two metals, due to the difference in the Fermi energies at thin near-surface area, in one of the metals, there is an excess of electrons, and in the second one, there is a shortage of them. Such a system is modelled by an effective capacitor [1-4]. A quantitative parameter of such an interaction is external contact potential difference (CPD), $\Delta \phi_{\text {ext }}$. For metals and semiconductors, it is determined as a difference for the contacting media, $\Delta \phi_{\text {ext }}=\left(A_{V 1}-A_{V 2}\right) / e$ [5], where $A_{V 1}, A_{V 2}$ are media electron work functions, $e$ is an electron charge.

However, due to the physical-chemical, thermodynamic, and mechanical incompatibility of contacting metals (semiconductors), there is an interaction between them, and interphase boundary is appear [3, 4], and it is modelled as interface capacitor. Therefore, the properties of metal boundaries will be quantitatively defined by the external $\left(\phi_{\text {ext }}\right)$ and internal $\left(\phi_{\text {int }}\right)$ contact potential difference (CPD) as well as a number of energy parameters: interfacial energy $W_{m}$, interfacial tension $\sigma_{m}$, energy of adhesive bonds $W_{a d}$, and work of adhesion [1, 5-8]. Certain correlation between these parameters is possible under consideration of mechanoelectrical nature of interface boundary [6, 7].

The relationship between the CPD and energy parameters (in particular, with surface energy) has practical interest in the study of contact phenomena: coating adhesion, diffusion, stresses relaxation, creep, corrosion properties, and diagnostics of the technical properties of the surface layers [1-9]. 
The internal CPD (Galvani potential) is approximately calculated as $\Delta \phi_{K}=\left|\left(E_{F 1}-E_{F 2}\right) / e\right|$, where $E_{F 1}$ and $E_{F 2}$ are the Fermi energies of insulated metals. It is calculated from the bottom of the conduction band of each metal or $\Delta \phi_{K}=\frac{h^{2}}{8 m_{e} e}\left(\frac{3}{\pi}\right)^{2 / 3}\left|n_{2}^{2 / 3}-n_{1}^{2 / 3}\right|$ [5], where $h$ is Planck's constant; $m_{e}$ is an electron mass; $n_{1}, n_{2}$ are free-electrons' concentration of contacting media.

According to $[10,11]$, internal $\operatorname{CPD} \Delta \phi_{\text {int }}$ (Galvani potential) is calculated as $\Delta \phi_{\mathrm{int}}=\frac{k_{B} T}{e} \ln \left(\frac{n_{1}}{n_{2}}\right)$, where $k_{B}$ is Boltzmann constant, and $T$ is Kelvin temperature. This equation, as well as $\Delta \phi_{K}$, gives an incorrect estimation of CPD, since electrostatic, kinetic, exchange, and correlation components of electron gas were not taken into account when it was derived $[8,12]$. According to [10], at room temperature, the inequality must be satisfied: $\Delta \phi_{\text {int }}<<\Delta \phi_{\text {ext }}, \Delta \phi_{K}<<\Delta \phi_{\text {ext }}$. However, the calculations based on the above ratios show that, for most of the contacting metal pairs, it is not fulfilled. In an addition, for many cases, $\Delta \phi_{\text {int }} \neq \Delta \phi_{K}$. In particular, it has been found that the typical averaged calculations of CPD for typical metal pairs are as follow: $\Delta \phi_{\text {ext }} \approx 1 \mathrm{~V}, \Delta \phi_{\text {int }} \approx 0.03 \mathrm{~V}$.

Based on the above results, the energy situation on the interface must be taken into account during CPD calculation. Therefore, authors of $[2,4]$, during evaluation of internal CPD $\Delta \phi_{\text {int }}$ for interface of different metal pairs, $\mathrm{Al}, \mathrm{Fe}, \mathrm{Cr}, \mathrm{Ti}, \mathrm{Ni}, \mathrm{Cu}, \mathrm{Zr}$, under 'condenser approach', made an attempt to establish the interconnection between CPD $\left(\Delta \phi_{\text {int }}\right)$ and interface energy $W_{\mathrm{m}}$. However, for the evaluation of interface layer, they used only electrostatic component of interphase energy, which, according to their assumption, is $100 \%$. At the same time, according to [1, 8, 12], for iron-copper contact, the electrostatic component of the interphase energy is only $0.2 \%$, and the main part $(99.8 \%)$ corresponds to the kinetic, exchange, and correlation components as well as the contribution of heterogeneity of the electron gas. In [6,7], a different approach is used in accordance with surface energy $W_{S}$ divided into two componentselectrostatic and mechanical ones. That is why, in the energy meaning, for the mechanical component, the additive (total) contribution of the kinetic, exchange, and correlation components as well as the contribution of heterogeneity of the electron gas corresponds to the mechanical component. For the boundary of each of these metals (Al, $\mathrm{Fe}, \mathrm{Cr}, \mathrm{Ti}, \mathrm{Ni}, \mathrm{Cu}, \mathrm{Zr}$ ) with an inert-gas environment, the average value of the electrical component of the surface energy is approximately of $65 \%$, and mechanical one is of $35 \%[6,7]$. There- 
fore, for the correct evaluation of the internal CPD, it is advisable to take into account the adequate values of the constituents (electric and mechanical ones) of interface energy in different combinations (for example, 'metal 1-metal 2', 'metal-inert-gas environment'). Furthermore, for the simulation of the interface capacitor for physical reasons, it is more appropriate to use internal CPD [5, 11], since it takes into account the situation on the boundary of the environments and does not require for calculations the values of the electron work functions on the contacting surface, the value of which has a significant dispersion [13].

The determination of energy parameters of the 'metal-metal' interface, evaluation of interface-capacitor internal CPD, and establishing interrelationships between them are the goal of this work.

\section{ENERGY PARAMETERS OF INTERPHASE INTERACTION. CONTACT POTENTIAL DIFFERENCE}

\subsection{Physicomathematical model of interphase boundary}

The energy parameters of the interface layers at the 'metal-metal (semiconductor)' boundary are calculated within the physicomathematical model. It is based on microscopic relations of nonequilibrium thermodynamics, mechanics of deformable body, and surface physics. They take into account the internal mechanical stresses caused by the redistribution of conduction electrons (or bounded charges in dielectrics) $[6,7,14,15]$.

The approach is based on separation of interface-layer energy $W_{m}$ and surface energy $W_{S}$ into two components, in particular, surface energy on the electrical $\left(W_{E}\right)$ and mechanical $\left(W_{D}\right)$ energies $[6,7$, $14,15]$. Electrical component $W_{E}$ is determined by the redistribution of conduction electrons and mechanical one $W_{D}$ is defined by tensor of mechanical stress $\hat{\sigma}$. In the first stage, according to [14, 15], we consider the system of 'metal-inert gas' with corresponding surface parameters. In the second stage, two metals are hypothetically brought into contact and analysing the interphase layer.

For 'metal-inert-gas medium', the expressions for surface tension energy $\sigma_{h}$, surface energy (SE) $W_{S}$, and the conditions of the surface layer equilibrium and surface layer effective thickness $h$ are as follow $[6,7,14,15]$ :

$$
\begin{gathered}
\int_{0}^{h} \sigma_{y} d x=\sigma_{h}, \sigma_{y}=\sigma_{z}, \\
W_{E}+\xi W_{D}=W_{S},
\end{gathered}
$$




$$
\begin{gathered}
\frac{\partial W_{S}}{\partial k}=\frac{\partial\left(W_{E}+\xi W_{D}\right)}{\partial k}=0, k=\sqrt{\frac{\rho C_{\phi}}{\varepsilon_{0}}}, \\
\sigma_{y}+p=0 \text { for } x=h .
\end{gathered}
$$

Here, $W_{E}=\int_{0}^{h} w_{E} d x$ is electrical component of SE and $W_{D}=\int_{0}^{h} w_{D} d x$ is mechanical one; $w_{E}=\frac{\varepsilon_{0}}{2}\left(\frac{\partial \Psi}{\partial x}\right)^{2}$ and $w_{D}=\frac{\sigma_{x}\left(\sigma_{x}-4 v \sigma_{y}\right)}{2 E}+\frac{(1-v) \sigma_{y}^{2}}{E}$ are densities of the electrical and mechanical components; $\sigma_{x}, \sigma_{y}$ are mechanical-stresses' tensor components; $x, y$ are Cartesian coordinates, and, in particular, $x$ is perpendicular to the boundary of the media; $h$-effective thickness of the surface layer; $\varepsilon_{0}$ is electric constant; $v=\frac{3 K-2 G}{2(3 K+G)} ; E=G \frac{3 K+4 G}{3 K+G} ; G, E, K$ are the compression, Young's, and shear moduli, respectively; $v$ is Poisson's ratio; $k$ is variation ratio [1, 15]; $\rho$ is specific density of a metal; $p=100 \mathrm{kPa}$ is atmospheric pressure; $C_{\phi}$ is specific electrical capacity; $\Psi$ is potential of electric field; $\xi$ is dimensionless parameter determined by a boundary problem $[6,7,14,15]$.

Equations (1)-(4) are used to determine changes of surface tension and energy.

Let us apply them to investigation of state parameters (like $k$ and $C_{\phi}$ ) and surface-layer geometric parameter $h$ at the boundary of 'metal-inert-gas medium' (of air type).

At the second stage of calculation of interphase energy $W_{m}$ and interphase tension $\sigma_{m}$, let us write them in the form $[14,15]$ :

$$
W_{m}=W_{m E}+\xi_{m} W_{m D} ; W_{m E}=\int_{-H}^{H} w_{E} d x ; W_{m D}=\int_{-H}^{H} w_{D} d x ; \sigma_{m}=\int_{-H}^{H} \sigma_{y} d x
$$

Here, $\xi_{m}$ is the physical parameter of interphase layer, $2 \mathrm{H}$-its effective thickness.

The energy of the adhesion bond $W_{a d}$ is given according to the definition $[14,15]$ :

$$
W_{a d}=W_{1}+W_{2}-W_{m}
$$

where $W_{1}$ and $W_{2}$ are surface energies of contacting metals.

The condition of equilibrium of interface layer and the approximate conditions on the boundaries, $x=H$ and $x=-H$, are written in the same way as Eqs. (3) and (4) [14]: 
$\partial W_{m} / \partial x=\partial\left(W_{m E}+\xi_{m} W_{m D}\right) / \partial x=0, \sigma_{y 1}+p=0(x=+H), \sigma_{y 2}+p=0(x=-H)$.

The conditions on the 'metal 1 -metal 2 ' boundary $[14,15]$ are:

$$
\phi_{1}+\Phi_{01}=\phi_{2}+\Phi_{02}, j_{1}=j_{2}, \sigma_{x 1}=\sigma_{x 2}, \sigma_{y 1}=\sigma_{y 2} .
$$

where $j_{1}$ and $j_{2}$ are densities of electric currents.

The equation (5)-(8) (taking into account the expressions for the surface and interphase tensions $[6,7,14,15])$ are used for evaluation of energy parameters of the interface layer and their changes under mechanical loads and diffusion processes.

\subsection{Evaluation of the internal contact potential difference}

Let us calculate the CPD by applying the interconnection between the interphase energy $W_{m}$ and surface electric-charge density $\Omega$, which is localized within the interphase capacitor $[14,15]$.

The electric component of surface energy $W_{m E}$ can be expressed by means of the surface electrical capacitor $C$ and potential $\Delta \Psi$ (Galvani potential) [16]:

$$
W_{m E}=C \Delta \Psi_{Y}^{2} / 2=\Omega^{2} /(2 C), C=\varepsilon_{0} k / 2, d_{\xi}=2 / k,
$$

where $d_{\xi}$ is effective distance between the plates of the capacitor (within the double electric layer).

The electrical capacitance $C$ of interface layer capacitor and potential difference $\Delta \Psi_{Y}$ (which is interpreted as internal CPD) are calculated by electrostatic equation $C=\Omega / \Delta \Psi_{Y}$ and numerical data

TABLE 1. Energy parameters of interface layers and contact potential difference calculated by different methods.

\begin{tabular}{c|cccccccc}
\hline Type & $W_{m}, \mathrm{~J} / \mathrm{m}^{2}$ & \multicolumn{2}{c}{$\sigma_{m}, \mathrm{~N} / \mathrm{m}$} & $W_{a d}, \mathrm{~J} / \mathrm{m}^{2}$ & $\Delta \phi_{\text {ext }}, \mathrm{V}$ & $\Delta \phi_{\text {int }}, \mathrm{V}$ & $\Delta \varphi_{K}, \mathrm{~V}$ & $\Delta \Psi_{Y}, \mathrm{~V}$ \\
\hline $\mathrm{Cr}-\mathrm{Fe}$ & 1.133 & 1.271 & 4.898 & 0.13 & 0.0180 & 4.218 & 0.297 \\
$\mathrm{Al}-\mathrm{Ni}$ & 0.682 & 0.765 & 3.138 & 1.11 & 0.00026 & 0.076 & 0.189 \\
$\mathrm{Fe}-\mathrm{Cu}$ & 0.658 & 0.735 & 4.004 & 0.17 & 0.0176 & 4.129 & 0.215 \\
$\mathrm{Al}-\mathrm{Fe}$ & 0.646 & 0.705 & 3.194 & 0.26 & 0.00159 & 0.477 & 0.186 \\
$\mathrm{Al}-\mathrm{Cr}$ & 0.598 & 0.652 & 4.113 & 0.26 & 0.0196 & 4.7 & 0.200 \\
$\mathrm{Zn}-\mathrm{Fe}$ & 0.521 & 0.566 & 3.363 & 0.255 & 0.00645 & 1.787 & 0.166 \\
$\mathrm{Al}-\mathrm{Cu}$ & 0.3 & 0.338 & 2.84 & 0.15 & 0.0191 & 4.606 & 0.142 \\
$\mathrm{Al}-\mathrm{Ti}$ & 0.291 & 0.318 & 2.569 & 0.09 & 0.0118 & 3.118 & 0.130 \\
$\mathrm{Zn}-\mathrm{Sn}$ & 0.185 & 0.201 & 1.778 & 0.135 & 0.00323 & 0.88 & 0.0951 \\
$\mathrm{Al}-\mathrm{Pb}$ & 0.163 & 0.175 & 1.573 & 0.25 & 0.0080 & 2.21 & 0.0825 \\
\hline
\end{tabular}


of $\Omega$. The values of three types of internal CPD for different pairs of contacting metals are shown in Table 1 .

\section{THE NUMERICAL DATA OF INTERPHASE ENERGY PARAMETERS AND CPD}

Energy parameters of interface layers and CPD can be calculated with the help of next parameters: Young modulus $E$, Poisson modulus $v$, surface tension $\sigma_{h}$ and surface energy $W_{S}$, specific density of a metal $\rho$, density of conduction electrons $n$, electron work function $A_{V}$, and Fermi energy $E_{F}$, which are given in [6,7, 13-20]. The results of calculations are given in Table 1 .

For some contacting pairs of metals, with relations (1)-(9) and some technique shown in $[6,7,14-16]$, the energy parameters of interface layer are evaluated, namely, interface energy $W_{m}[4,19]$, interface tension $\sigma_{m}$ [17], and energy of adhesion bond $W_{a d}[19,20]$; in particular,

$$
\begin{gathered}
W_{m}(\mathrm{Cu}, \mathrm{Al})=0.3 \mathrm{~J} / \mathrm{m}^{2}[4], \sigma_{m}(\mathrm{Zn}, \mathrm{Sn})=0.20 \mathrm{~N} / \mathrm{m}, \\
W_{a d}(\mathrm{Fe}, \mathrm{Cu})=W_{S}(\mathrm{Fe})+W_{S}(\mathrm{Cu})-W_{m}(\mathrm{Fe}, \mathrm{Cu})=4.0 \mathrm{~J} / \mathrm{m}^{2}, \\
W_{a d}(\mathrm{Cu}, \mathrm{Al})=2.78 \mathrm{~J} / \mathrm{m}^{2}[19], W_{a d}(\mathrm{Fe}, \mathrm{Cr})=5.06 \mathrm{~J} / \mathrm{m}^{2} .
\end{gathered}
$$

The numerical calculation of energy parameters of interface layers and CPD $\Delta \phi_{Y}$ and CPD $\Delta \phi_{\text {int }}, \Delta \phi_{K}, \Delta \phi_{\text {ext }}$ carried out with procedure [1] based on above equations are given in Table 1 .

The values of internal CPD $\left(\Delta \phi_{\text {int }}, \Delta \phi_{K}, \Delta \phi_{Y}\right)$ calculated by different methods are differ significantly with each other according to the data shown in Table 1.

To understand the relationship between the energy parameters of the interphase layer and the calculated values of CPD $\left(\Delta \phi_{Y}\right)$, let us carry out the data analysis of Table 2 . The cross-correlations analysis had shown that connection between the energy parameters $W_{a d}$, $\sigma_{m}, W_{m}$ and CPD $\Delta \phi_{\text {ext }}, \Delta \phi_{\text {int }}, \Delta \phi_{K}$ is absent. Nevertheless, between interface energy $W_{m}$ and $\operatorname{CPD}\left(\Delta \phi_{Y}\right)$ as well as between $W_{m}$ and $Q_{m} / Q_{C}$, the essential correlation is observed. The corresponding values of linear correlation coefficients taking into account the numerical data ranking are as follow:

$$
K\left(W_{m}, \Delta \phi_{Y}\right)=0.98 ; K\left(W_{m}, Q_{m} / Q_{C}\right)=0.85 .
$$

The obtained data indicate that the application of CPD $\left(\Delta \phi_{Y}\right)$ is more correct to describe the interface layer than the parameters $\Delta \phi_{\text {int }}$ and $\Delta \phi_{K}$.

To fulfil the physical picture on the boundary of contacting met- 
TABLE 2. The relative number of electrons diffusing through the interface layer on the distance $D$ between the plates of interface capacitors.

\begin{tabular}{c|c|c|c|c|c}
\hline Type & $\mathrm{Al}-\mathrm{Ni}$ & $\mathrm{Al}-\mathrm{Fe}$ & $\mathrm{Cr}-\mathrm{Fe}$ & $\mathrm{Al}-\mathrm{Cr}$ & $\mathrm{Zn}-\mathrm{Fe}$ \\
\hline$Q_{m} / Q_{C}, \%$ & 2.07 & 2.02 & 1.99 & 1.87 & 1.78 \\
$D, \mathrm{~nm}$ & 0.0149 & 0.0153 & 0.0240 & 0.0192 & 0.0165 \\
\hline Type & $\mathrm{Fe}-\mathrm{Cu}$ & $\mathrm{Al}-\mathrm{Ti}$ & $\mathrm{Zn}-\mathrm{Sn}$ & $\mathrm{Al}-\mathrm{Pb}$ & $\mathrm{Al}-\mathrm{Cu}$ \\
\hline$Q_{m} / Q_{C}, \%$ & 1.76 & 1.52 & 1.480 & 1.475 & 1.45 \\
$D, \mathrm{~nm}$ & 0.0213 & 0.0164 & 0.0143 & 0.0125 & 0.0192 \\
\hline
\end{tabular}

als, let us evaluate the number of electron diffused through that layer. Let us calculate the number of electron on the boundary of 'metal-inner-gas environment' and 'metal ${ }^{(+)}-$metal $^{(-)}$', by [1]. For surface charges and relative number of electrons $Q_{m} / Q_{C}$ diffused through the $\mathrm{Zn}-\mathrm{Fe}$ interface layer, we have:

$$
\begin{gathered}
Q_{S}(\mathrm{Fe})=0.591 \mathrm{C} / \mathrm{m}^{2} ; Q_{S}(\mathrm{Zn})=0.411 \mathrm{C} / \mathrm{m}^{2} ; Q_{C}(\mathrm{Fe}, \mathrm{Zn}) \equiv Q_{C} ; \\
Q_{C}=\left(Q_{S}(\mathrm{Fe})+Q_{S}(\mathrm{Zn})\right) / 2=0.501 \mathrm{C} / \mathrm{m}^{2} ; Q_{m}=0.00891 \mathrm{C} / \mathrm{m}^{2} ; \\
Q_{m} / Q_{C}=0.00891 / 0.501 \approx 1.78 \% .
\end{gathered}
$$

Here, $Q_{S}(\mathrm{Fe})$ and $Q_{S}(\mathrm{Zn})$ are surface charges of metals contacting with inert-gas environment (air) at pressure $p_{c}=100 \mathrm{kPa} ; Q_{C}$ is the average value of the surface electric charge; $Q_{C}$ is interface charge. For other contacting metals, the calculation results are given in Table 2 .

As we can see in Table 2, the relative number of electrons diffusing through the interface layer is around $Q_{m} / Q_{C}=1.45-2.07 \%$ that is well agree with $\left(Q_{m} / Q_{C} \cong 2 \%\right)$ [21]. At the same time, similar evaluation of interphase charge $Q_{m}$ and distance $D$ based on data of $\Delta \phi_{\text {int }}$ and $\Delta \phi_{K}$ do not match with value $Q_{m} / Q_{\mathrm{C}} \cong 2 \%$.

As far as $\Delta \phi_{K}$ is of almost an order of magnitude larger than $\Delta \phi_{Y}$, and $\Delta \phi_{\text {int }}$ is of an order of magnitude smaller than for $\Delta \phi_{K}$, $Q_{m} / Q_{C} \cong 20 \%$ and $\Delta \varphi_{\text {int }}-Q_{m} / Q_{C} \cong 0.2 \%$. That is why, the data like $\left(Q_{m} / Q_{C} \cong 20 \%, Q_{m} / Q_{C} \cong 0.2 \%\right)$ is physically incorrect.

\section{CONCLUSIONS}

Energy parameters of interface layers for contacting metals $(\mathrm{Cr}, \mathrm{Fe}$, $\mathrm{Al}, \mathrm{Ni}, \mathrm{Cu}, \mathrm{Zn}, \mathrm{Ti}, \mathrm{Sn}$ ) assuming two additive components of interphase energy (electrical and mechanical ones) were calculated. Internal contact difference of potential (CPD) $\Delta \phi_{Y}$ between metals taking in account interphase interaction was estimated. A comparative analysis of $\Delta \phi_{Y}$ with $\Delta \phi_{\text {int }}$ and $\Delta \phi_{K}$ has been carried out. 
As shown, the relative number of electrons diffusing through the interface layer of metals does not exceed $2 \%$ of their total electron value in the metal near-surface layer, which is in contact with the inactive gas medium.

High correlations between phase energy $W_{m}$ and CPD $\Delta \phi_{Y}(0.98)$ and between $W_{m}$ and relative interphase electric charge $Q_{m} / Q_{C}$ $(0.85)$ were found.

For correct description of the metal interface and evaluation of electrical component $W_{e m}$ and interphase charge $Q_{m}$ by utilize of 'condenser' approach, the internal CPD $\Delta \phi_{Y}$ should be used.

\section{REFERENCES}

1. $\quad$ M. B. Partenskii, Sov. Phys. Usp., 22: 330 (2014).

2. A. A. Klypin, A. A. Luczina, Proc. of the USSR Academy of Sciences. Series 'Metals', 23, Iss. 2: 138 (1985) (in Russian).

3. R. Parsons, Chem. Rev., 90: 813 (1990).

4. S. A. Nevsky, S. V. Konovalov, and V. E. Gromov, Journ. Technical Physics, 6: 133 (2011) (in Russian).

5. P. Pelco, J. A. Manzanares, and H. H. Girault, Langmuir, 32: 5765 (2016).

6. $\quad$ B. P. Koman and V. N. Yuzevich, Phys. Sol. St., 54: 1335 (2012)

(in Russian).

7. V. N. Yuzevich and B. P. Koman, Phys. Sol. St., 56: 895 (2014) (in Russian).

8. $\quad$ N. C. Lang and W. Kohn, Phys. Rev. B, 1: 3555 (1970).

9. R. Dzhala, V. Yuzevych, M. Melnyk, Bulletin of Lviv Polytechnic National University. Series 'Computer Sciences and Information Technologies', 826: 185 (2015) (in Ukrainian).

10. G. Job and R. Rüffler, Physical Chemistry from a Different Angle. Ch. 22. Electrode Reactions and Galvani Potential Differences (Switzerland: Springer International Publishing: 2016), p. 521.

11. J. R. Smith, Phys. Rev., 181: 522 (1969).

12. Tables of Physical Quantities (Ed. I. K. Kikoin) (Moscow: Atomizdat: 1976) (in Russian).

13. V. Yuzevych, I. Ogirko, and R. Dzhala, Physical and Mathematical Modelling and Information Processes, 13: 173 (2011) (in Ukrainian).

14. B. P. Koman and V. M. Yuzevich, J. Nano- Electron. Phys., 7, No. 4: 04059 (2015).

15. B. P. Koman, V. M. Yuzevich, and R. M. Dzhala, J. Nano- Electron. Phys., 8, No. 4: 04005 (2016).

16. C. Kittel, Introduction to Solid State Physics. 8th Edition (USA: John Wiley \& Sons, Inc.: 2004).

17. H. L. Skriver and N. M. Rosengaard, Phys. Rev. B, 46: 7157 (1992).

18. N. Eustathopoulus and J.-C. Joud, Current Topics in Material Science. Vol. 4. Interfacial Tension and Adsorption of Metallic Systems (Ed. E. Kaldis) (Amsterdam: 1980), p. 281.

19. A. N. Vakilov, M. V. Mamonova, and V. V. Prudnikov, Phys. Sol. St., 39: 864 (1997). 